\title{
Cruces normativos y dialectales en la Proclama del chusco de Arequipa (c. 1810)*
}

\author{
Juan Antonio Frago** \\ Universidad de Zaragoza, España
}

\begin{abstract}
Resumen
Forma parte esta Proclama de una relación de Arequipa redactada en tierras americanas por Pereira Pacheco, clérigo canario, poco antes de regresar a España en 1816. Pues bien, en esta sátira literaria se alude a un hablar de los camanejos, proclamado rústico en el título, que no llega a materializarse en dicho texto, en el cual, sin embargo, se advierten rasgos del uso americano general y del de este dominio peruano, trufados de notas características de la modalidad isleña del copista. En su vocabulario arequipeño y en toda la Noticia de Arequipa son varios los datos referentes al área costeña del Perú de los años en que se combate por la Independencia, muestras también de la variación normativa y dialectal que el español de América presenta entre sus regiones y en relación con la diversidad diatópica del español europeo.
\end{abstract}

Palabras clave: entre Canarias y Arequipa, español de América en la Independencia, variación normativa y dialectal.

* Del proyecto FFI2011-24806, Ministerio de Economía y Competitividad.

** Para correspondencia dirigirse a: Juan Antonio Frago Gracia (jafrago@unizar.es), Departamento de Lingüística General e Hispánica, Facultad de Filosofía y Letras, Universidad de Zaragoza, Pedro Cerbuna 12, 50009 Zaragoza, España. 


\title{
Normative And Dialectal Crossing IN THE CHUSCO DE AREQUIPA \\ Proclamation (C. 1810)
}

\begin{abstract}
This Proclamation is part of an account from Arequipa written in America by Pereira Pacheco, a Canary Islands clergyman shortly before his return to Spain in 1816. In this literary satire the camanejo way of speaking, named rustic in the title, is alluded, but it does not materialize in the text. Nevertheless, we can observe in it some traits of the speech found in America and in this Peruvian region, full of notes characteristic of the Canarian copyist. In his Arequipeño vocabulary and across Noticia de Arequipa, there is a lot of information about the coastal area of Peru during the fight for independence, an indication of the normative and dialectal variation American Spanish presents in its regions and in relation to the diatopic diversity of European Spanish.
\end{abstract}

Key words: Canary Islands and Arequipa, American Spanish during the Independence, normative and dialectal variation.

Recibido: $15 / 11 / 11 \quad$ Aceptado: 03/05/12

\section{EL CORPUS ${ }^{1}$}

Proclama que un chusco de Arequipa dio a luz en boca de los camanejos, tenidos en este Reyno como en España los gallegos.

Cristianos: ya se desponchó la indigna y depravada codicia de ese bruto de Bonaparte, quien, después de haber prometido a la nación española ser

1 La Proclama chusca se incluye en la Noticia de Arequipa de Pereira Pacheco (fs. 57-59v). Hay una edición reciente de Hernández González (2009), con algunas incorrecciones, pero la primera completa fue de Carrión Ordóñez (1983), hecha con notable rigor y acompañada de excelente estudio lingüístico, sobre copia fotográfica del original, de la Biblioteca Nacional de Lima, con intento anterior de Alejandro Lostaunau (Fénix, 1946, 813-838). El autógrafo procede de Güimar, propiedad que fue de Vicente Hernández Jorge, descendiente de Pereira, actualmente en colección particular (González Yanes 2002: 134). 
su compa (a) hasta la muerte, ha faltado a su palabra, el impávido (b) sin vergüenza, queriendo capujarle (c) a Señor Fernando, nuestro Rey, el trono que el mismo cielo le dio, para encaramar en él al buen alaja de tío Chepe (d). ¡Qué atrevimiento! ¿Qué desvergüenza! Pero esto y la cara de Dios no verá el hijo de p., fantástico picarón. ¡Con los españoles se ha puesto! Muy buena gente es; no está con gagos; ellos le harán ver su gran cagada. Guapos son, y no cobardes. Tiemble pues su valentía, que en tocándoles a pelear, no es por // (f. $57 \mathrm{v}$ ) alabarles, no sólo le vencerán, sino que le pondrán de suerte que no pueda servir ni para zapatero viejo.

Nosotros estamos lejos de la Península, pero entre nosotros mismos, gracias a Dios, brilla el valor, de tal modo que hierve en nuestras mismas venas mejor que la miel en los peroles. Ojalá le pescáramos aunque fuese a lazo a ese canalla, mala casta, presumido, que a más de ponerle una buena osiquera y alcabagarle con un aparejo viejo, le claváramos dos tercios famosos de camotes (a) y un soborno de diez arrobas de yucas (b), y aunque con el peso se empacase (c), lo auxiliaremos y, como quien no quiere la cosa, le ayudaríamos también con una buena su[r]riaga, cascándole por el rabo hasta el término de desollarlo; y vería entonces el demonio del ladronaso en qué mal se había metido, y con quién trataba.

\section{// (f. 58)}

En esto, más que en otras cosas, hemos manifestado siempre nuestro talento y sabiduría. Nuestras fuerzas han sido tan admirables, que aún los mismos animales de nuestras recuas, con ser más fuertes que todos nosotros juntos, nos han temido. No obstante que sus discursos han sido iguales a los nuestros, nuestra industria ha preponderado en extremo por la misericordia de Dios, y somos tan diestros en el manejo del cabrestillo, que con él hacemos llorar sangre a las piedras y a los troncos, y quando estamos enfrascados y con la mostaza en la frente, somos capaces de hacer hipar a las ánimas benditas del purgatorio, a punta de látigo quitarles el chúccho (a) que padecen. Así somos, y, por Dios bendito, si este vil traidor cayera a nuestras manos, no se viera de polvo, ni se riera; tubiera, sí, bastante sarna que rascar, y se acordara muy bien de la mala p. que lo parió y del genísaro cabrón que lo engendró.

Ojalá N. S. de los Dolores, y la alma de Santa Rosa de Lima, nos hiciera el flaco servicio de ponernos en los pantanos de la Dehesa a ese Bonaparte, a ese chasca (b) atrevido, a ese vil // (f. 58v) motilón, para atollarlo allí, de modo que, sin poder decir Jesús, en un santiamén fuese a resollar a los infiernos, a acompañar a su gran maestro Judas, que hizo con Nuestro Señor Jesucristo lo mismo que este malvado pretende practicar con los borbonistas, 
con esos manzos corderos, ovejas de nuestro rebaño, a quienes después de haberlos sacado con engañifas de Madrid y llevádolos a su inicua Francia, para que se divirtiesen y paseasen a pierna suelta a su gusto, lueguito en el momento los apigualó (a), prometiéndoles continuas amenazas el catatarlos y despuecuesarlos (sic) con esa su maldita media luna, que tanto horror causa, y a consequencia de este depravado intento solicita este monstruo de todos los diablos gobernarnos y hacernos sus esclavos. ¡Ay!, qué mal piensa este demonio; no somos guaguas (b), bien mancarrones somos, no nos meterá los dedos en la boca; lo mexor es que su intención está bien conocida.

Por esto, hermanos, ante todas cosas, ojo al grano; hagamos plata vendiendo nuestros aperos, lomillos, aparejos, sen-// (f. 59) cerrillos, cascabeles; no reservemos nada de lo más precioso que poseemos, y si es dable aún a nosotros mismos alquilémosnos en chancacas (a) y alfeñiques, para que, convertido todo en pesos, mandemos nuestras limosnas para socorrer a los que están en España peleando por arrancar a nuestro Rey, a nuestro amado taitito el Señor Fernando, que se halla cautivo entre esos bárbaros. Y para mayor honra y gloria de Dios y extirpación de las heregías y aumento de la religión católica apostólica romana, remontémosnos a las lomas con el insigne y glorioso Patriarca San Saturnino, que es nuestro patrón y benefactor, y para que nos oiga y sepa hablar bien por nosotros, atolondrémoslo con aullidos y llorémosle con él a Jesucristo, que al fin, como es tan bueno, nos ha de mirar con ojos de manza paloma, y quemando la espada de su justicia nos amparará y hará conocer que sabe atacarse los calzones en los casos más apretados.

Sobre todo, para que consigamos un feliz despacho es necesario que nos abstengamos de bailar con espuelas (b), de hacer temblar a la // (f. 59v) media noche a los pobresitos olivos (a), que no comamos carne de cuchi (b) y tamales de arroba (c), que tanto nos gusta, y que el guarapo (d), que demasiado nos alegra, no se nos ponga a los ojos, pues tiempo hay para todo. Aprontemos, sí, hermanos, nuestras reatas y lazos para ensartar en ellos las cuentas redondas del rosario de nuestra Madre y Señora de Mercedes, que son balas de artillería, diciendo sin descansar aquella hermosa oración "el ángel del Señor anunció a María", con sus tres "Dios te salve María"; que con esto, y afianzados en los tres tenedores (e) y en la pelota (f) del Niño Jesús, harán las armas españolas maravillas y destrosos en los malditos franceses, y conseguiremos una cumplida victoria. Amén.

(a) Compañero. (b) Atrevido, sin temor. (c) Arrebatar. (d) Así llaman aquí a los Josées (f. 57).

(a) Batatas. (b) Raíz muy blanca, harinosa y más dulce que la batata. (c) tómanlo aquí por quedarse una vestia parada y sin querer andar (f. $57 \mathrm{v}$ ). 
(a) Frío con temblor. (b) cabeza desgreñada (f. 58).

(a) Aprisionar. (b) Criaturas chicas (f. 58v).

(a) Ciertos alfeñiques hechos con la miel sin purgar. (b) Acostumbran bailar con espuelas, que son bien grandes y cuyo ruido lleva gran compaz con los instrumentos (f. 59).

(a) No pierden vasa en robar azeitunas. (b) Cochino. (c) Maza hecha con maíz y azúcar. (d) Dan este nombre a la bebida que hacen echando agua a los residuos de la miel de caña. (e) Resplandores que se pone en las cabezas de los Niños Jesúes. (f) El mundo que lleva en la mano el Niño (f. 59v).

\section{LA FORMA Y EL FONDO. ENTRE EL TÓPICO Y LA VERACIDAD HISTÓRICA}

2.1. Esta pieza satírica como queda dicho (cfr. n. 1) es parte de la Noticia de Arequipa (en adelante Noticia) del ilustrado tinerfeño Antonio Pereira Pacheco (La Laguna, 1790-Tegueste, 1858), que redactó su manuscrito el año 1816, siendo beneficiado de la Catedral de Arequipa y notario del Santo Oficio de su partido. El joven seminarista canario había llegado al Perú en 1810 junto a su hermano Miguel y varios clérigos isleños, como paje del titular de la diócesis arequipeña, su protector grancanario Luis González de la Encina, tras cuyo fallecimiento, ocurrido el 19 de enero de 1816, Pereira embarcaría en El Callao de regreso a España el 13 de noviembre del mismo año (Hernández González 2009: 17, 20).

El texto lleva anotadas a pie de cada folio, con llamadas de orden alfabético, definiciones de voces y explicaciones de ciertos usos y costumbres locales, y Pereira parece haber pensado en una edición de su manuscrito e ilustraciones al retorno a su tierra natal. Las partes anotadas son, en este orden: compa, impávido, capujar, Chepe (f. 57); camotes, yucas, empacase (f. 57v); chuccho, chasca (f. 58); apigualó, guaguas (f. 58v); chancacas, bailar con espuelas (f. 59); hacer temblar a la media noche a los pobresitos olivos, cuchi, tamales de arroba, guarapo, los tres tenedores, la pelota del Niño Jesús (f. 59v).

Pocas erratas hay en la Noticia y escasas correcciones también, muy probablemente debidas al autor. En cuanto a la Proclama, apenas una enmienda en empacase, que hace dudar en una lectura empacare, y el descuido en despuecuesarlos, quizá por anticipación del diptongo/ue/ de la 
sílaba siguiente. Y queda el posible error de copia que supondría auxiliaremos por auxiliáramos (cfr. n. 16).

2.2. La ortografía de esta Proclama paródica es idéntica a la del resto de la Noticia y a la que Pereira usó antes de partir rumbo al Perú y después de regresar a Canarias. Se trata, por consiguiente, de la que aprendió en su formación isleña, sobre todo en los años de estudio en el prestigioso seminario conciliar de Las Palmas. No solo emplea los dos puntos (:) para indicar el estilo directo, sino en ocasiones también como signo equivalente de la coma, el punto y coma y el punto y seguido: "Cristianos: ya se desponchó la indigna y depravada codicia de ese bruto de Bonaparte" "¡Con los españoles se ha puesto! Muy buena gente es: no está con gagos: ellos le harán ver su gran cagada" (f. 57), "¡Ay, qué mal piensa este demonio!: no somos guaguas" (f. 58v). Tilda regularmente la preposición $a$, así como las voces agudas y llanas, en línea con lo que fue extendida corriente ortográfica dieciochesca, verbigracia en desponchó, nación, vencerán y camanéjos, camótes, óiga, sobórno, y sistemáticamente emplea la diéresis o crema para señalar la pronunciación de la /u/ de diptongos precedidos de /k, g/, si bien asimismo en secuencias no contempladas en las reglas de la Academia, concordancias y discordancias ortográficas que por otro lado eran corrientes en la escritura de los cultos a uno y otro lado del Atlántico: conseqüencia, cüentas, inicüa, recüas y apigüaló, güagüas, güapos, güarapo; en ilustración de 1815 cüatro, perüano y antigüo en otra de 1817; ciüdad escribe el año 1809, poco antes de su salida de Canarias, y sitüado en 1833 (González Yanes 2002: 202, $213,233,284)^{2}$.

Es, pues, la ortografía de un individuo culto, que, como tan frecuente era en la época, se muestra seguidor de una lengua escrita en buena medida grafémicamente innovadora, al tiempo que continuador, por la enseñanza recibida en el banco escolar y en sus lecturas, de algunos usos anclados en la tradición, que no prosperarían en la ortografía más tarde hecha efectivamente general en el mundo hispánico. Pero debe insistirse en el hecho de que tal

2 Realmente, ya con anterioridad se venía practicando esta puntuación, sobre todo en la letra impresa, que la Real Academia Española recién fundada recogería en lo fundamental (1726-1739/1969: LXIV-LXV). La acentuación de Pereira coincide con la defendida en el Autoridades, salvo en el tildado de los esdrújulos, y en la Proclama el canario pone tres puntos seguidos a la $p$ con que en dos ocasiones abrevia puta. En mi estudio regularizo con las actuales pautas la puntuación y la acentuación. 
compartición de variantes fue moneda corriente en los mejores escritores dieciochescos y de la primera mitad del XIX.

No desmerece del nivel cultural que se atribuye al clérigo canario el que pusiera algunos adjetivos y nombres comunes con mayúscula --Camanejos, Camotes, Compa, Chusco, Guapos, Peroles, etc.--, que ocasionalmente escribiera tubiera, vasa 'baza', vestia 'bestia' con truque de $b$ y $v$, y alaja, osiquera $\sin h$, que representara de cuando en cuando la vibrante múltiple intervocálica con $r$ (suriaga), igual que guerilla 'guerrilla' en el plano de la acción del Cerro Cagro del pueblo de Asillo, en 1815 (González Yanes 2002: 229), vireyna en su vocabulario arequipeño, ni que en otros manuscritos de Pereira se registre la variante virrey-virrei y mui, o empleara a veces la $v$ vocálica (vniformidad). Sería, en efecto, anacrónico considerar tales "faltas" como indiscutibles evidencias de la incuria ortográfica de este personaje, cuando, como digo, parecidos se daban en individuos de selecta formación intelectual, tanto en América como en España, incluidos miembros de la misma Real Academia Española, y distaba el tiempo en que fueran de general aceptación las reglas académicas, a la sazón en varios aspectos cambiantes todavía, subsistiendo de la manera más natural atávicos usos escriturarios sin auténtica o rigurosa coerción normativa ${ }^{3}$.

\subsection{AUtORÍA Y TRANSMISIÓN TEXTUAL}

El autor de la chusca Proclama a no dudarlo era criollo, según su lengua a las claras demuestra, y muy probablemente de la misma Arequipa conforme afirma su título y se indica en la referencia que Pereira hace al texto satírico en la descripción de Camaná de la Noticia:

Se contempla a la gente de Camaná en su inteligencia y producciones como a los gallegos en España. De esto se valió un chulo de Arequipa para haber dado a luz, al principio de la guerra en España contra Napoleón, una proclama en los términos e inteligencia que podía producirla un camanejo, y es como se ve al número 57 (f. 43v).

3 Ni siquiera se siguen con rigor las normas de la Real Academia Española en los mismos informes que Antonio Angulo e Ignacio Cevallos le presentaron sobre el proyecto de su primera gramática (1771/1984: 497-534). Aparte de los cambios que en la materia fue adoptando la institución, por ejemplo para el uso de la diéresis en 1741, 1763 y 1815. 
El clérigo isleño en este trecho añadido al manuscrito de la Noticia se limita a copiar con meticulosidad la pieza paródica de creación ajena, meticulosidad que se advierte en la remisión que hace al folio en el que efectivamente se encontrará, lo cual parece indicar que su obra fue primeramente escrita en borrador y luego puesta en limpio, quizá con la intención de darla después a la imprenta, como antes he sugerido.

Así, pues, al final de la Noticia y a continuación de dos canciones bailables y de una composición musical igualmente copiada ${ }^{4}$, Pereira recoge la burlesca Proclama, seguramente por el interés literario y lingüístico que vio en ella, pero también por su significación política, sin contar con la inclinación etnográfica que en su Diario y en toda su obra erudita, epistolar y pictórica demostró el ilustrado eclesiástico, quien en modo alguno se atribuye la autoría de estas curiosidades, mientras que sí le corresponde en todo lo demás de la Noticia, así como en su relación de los Nombres provinciales de la ciudad de Arequipa (fs. 48a-f), culminación de la descripción arequipeña demostrativa de la atracción que sintió por la variedad diatópica y social de la lengua.

\subsection{El MARCO HISTÓRICO}

El texto de la Proclama no lleva fecha, porque no constaría en el que Pereira manejó para su traslado, pero, al apuntar que se compuso "al principio de la guerra en España contra Napoleón", su composición debe situarse alrededor de 1810. A la realidad histórica responde la arenga del camanejo a favor de una colecta para ayudar a quienes combatían con el francés en la Península, manifiesto alarde de fidelidad monárquica muy arraigada en no pocos criollos, pues suscripciones populares en apoyo de la legitimidad borbónica y de la resistencia contra la invasión napoleónica del suelo peninsular efectivamente se hicieron en distintas partes de América ${ }^{5}$. De

4 Son "El Moro", bayle de Arequipa y "El Cielito", bayle de Potosí, amén de "El Gallinasito”, baile de Arequipa, este con música pero sin letra (fs. 53-55).

5 Entre los numerosos testimonios referentes a Nueva España están las cartas de Francisco Venegas a Juan Martín el Empecinado sobre la suscripción abierta en México a favor de este caudillo, de 1811 y 1812, así como la carta de Juan Felipe Laurnaga y Julián Antonio de Llano, en que participan haber registrado en el navío Miño 17.900 pesos para el mismo guerrillero, en Veracruz el 12 de mayo de 1812: Biblioteca Nacional de España (BNE), Mss. 18.665-67, 18.665-58. También en el Perú se hicieron colectas para el sostenimiento del esfuerzo militar contra el invasor, y para el mismo Empecinado es la que se solicita en julio de 1811: BNE, Ms. 18.665-52. 
hecho, en la Noticia el mismo Pereira encomia la "lealtad al Soberano" del "bello sexo de Arequipa":

Cuantas veces se ha visto el herario en necesidad de auxilios para sostener los derechos del trono español, otras tantas han sabido las arequipeñas desprenderse con generosidad voluntariamente de sus alajas, cediéndolas en donativo (f.7).

Tampoco supone un motivo de ficción literaria la animadversión hacia la figura de Napoleón, Sapoleón sería llamado en décimas bogotanas independentistas de $1814^{6}$, sentimiento que no solo embargaba, pues, a los partidarios de la causa española, sino que por diversas razones participaron de él declarados patriotas americanos, así el anónimo autor del catecismo político bonaerense de 1811, “el infernal Napoleón” escribe, o José Amor de la Patria, quien en el suyo del mismo año vitupera la "perfidia de Bonaparte" en su invasión de España y todas sus demás conquistas de Europa (Sagredo Baeza 2009: 60, 79-80).

En la equiparación de camanejos y gallegos por su común rusticidad, condición a la que se solía asociar el baldón de la falta de luces en individuos de las comunidades de tal guisa tachadas ${ }^{7}$, no deja de haber un poso de realidad histórica, no porque las gentes de uno y otro dominio fueran más rudas y torpes que sus vecinos, sino porque el estereotipo, al menos en el caso de los gallegos con un claro trasfondo lingüístico, ciertamente existió, y desde luego la figura del gallego frecuentó los versos de una literatura, por lo general menor, ordenada a la comicidad de exagerados tipismos y "lenguajes" exóticos o marginales, con frecuencia adrede retorcidos en arbitrarias jergas. Por aquel escenario de tipos y de tópicos desfilaba el sayagués, el negro bozal y el morisco, el gitano ceceoso, el vascongado con sus discordancias, el francés de hablar macarrónico y otros personajes del género, entre los que no faltaba el de expresión galaica con su gaita (Frago 1986).

El negativo cliché sociológico del gallego se había transmitido de España a América por vía de la erudición literaria, pero también por el eco que el tópico llevaba en boca de naturales de otras regiones, transferencia plasmada

6 Las comento en artículo ahora en prensa en Onomázein, revista de la Pontificia Universidad Católica de Chile.

7 En la Noticia el punto de comparación entre camanejos y gallegos es "su inteligencia y producciones" (f. 43v), clara alusión, por más que meramente tópica, a su pretendida cortedad mental, de donde habría de seguirse pobreza e incorrección idiomática según el asendereado lugar común. 
en la siguiente observación del militar y político vascongado Anglés y Gostari sobre un jesuita de la provincia paraguaya:

En la dicha estancia de Yariguá asiste el padre Hilario Vázquez de muchos años a esta parte. Es gallego de los más refinados que han salido de su tierra y muy conocido por su gran miseria, por el mal estilo y por el rigor y desatención con que trata y procede con los españoles $(1769 / 2007: 27)^{8}$,

especie que encontró favorable caldo de cultivo allá donde la inmigración de gallegos fue más numerosa y los desplazados hubieron de dedicarse a oficios de bajo aprecio social, como en el Río de la Plata ocurrió desde algunos años antes de la Independencia (De Cristóforis 2010). Algo parecido, pero sin la consideración fuertemente despreciativa que los de dicha procedencia regional llegaron a tener en ciertas partes de América, se verificó en Andalucía, a cuyas ciudades afluyeron no pocos gallegos, habiendo sido motivo allí su gentilicio de una polisemia despectiva (Alvar Ezquerra 2000: 391) ${ }^{9}$.

Es lo que sucedió en Cádiz, ciudad de gran importancia comercial en el período colonial, donde un vocabulario decimonónico incluye gallego 'mozo de cordel o ganapán, por ser en Cádiz gallegos los ganapanes', 'gran hastío que ocasiona pereza' (Castro y Rosal 1857). Y en esta misma obra, donde se describe la calle gaditana del Corralón de los Carros, "célebre en ciertas épocas por citarse en la canción del Trágala que se cantaba a los serviles y que más de una vez oyó el rey Fernando VII durante la segunda época constitucional", se citan estos versos:

$$
\begin{aligned}
& \text { Ya no la arrancan } \\
& \text { ni con palanca, } \\
& \text { ni los gallegos } \\
& \text { del Corralón (53). }
\end{aligned}
$$

De toda evidencia es que el mal estilo achacado por Anglés y Gostari al jesuita gallego destinado en el Paraguay se está refiriendo a su expresión en castellano, quizá ya no solo por la tópica y asendereada condena lingüística que el hecho diferencial con frecuencia acarreaba, sino como resultado

8 Pero cuántas puyas sobre el carácter de los "vizcaínos", tan estereotipadas como las demás, y particularmente sobre el peculiar modo de hablar castellano de muchos de ellos, no corrieron lo mismo en el verso que en la prosa de aquellos siglos.

9 El significado de 'cobarde' que para gallego recoge este autor también es usual en hablas de Aragón y de Navarra, y seguramente en otras regiones. 
del conocimiento que el general vasco pudo tener de aquel miembro de la orden jesuítica, que seguramente practicaría un bilingüismo imperfecto. Comoquiera que sea, en el informe que Ignacio Cevallos (él se firma Ceballos) por entonces presentó sobre la que sería primera gramática de la Academia, al discutir muy someramente sobre los dialectos de la lengua española, este académico sostiene:

no son reconocidos como perfeción de la lengua, sino como vicio suio; entre los griegos se disputaba quál era mejor de los dialectos y en España solo se podrá disputar quál es el peor, porque los gallegos retienen solo entre los vulgares un dialecto que tiene gusto de rancio y viejo (Real Academia Española 1771/1984: 531) ${ }^{10}$.

De primordial interés para el comercio y las comunicaciones americanas fue el oficio de la arriería, con el que se identifica a los camanejos en la Proclama aquí estudiada ${ }^{11}$. Se sitúa Camaná en la Noticia "siguiendo la costa del sur, aunque algo apartada de sus playas", precisando Pereira que "sus tierras se dilatan por el oriente hasta los primeros cerros de la Cordillera". Localización, pues, idónea para que los camanejos se dedicaran al transporte por el litoral y hacia las tierras altas con sus recuas, siendo que "el principal comercio de esta provincia consiste en crecidas porciones de burros, que se crían y alimentan en sus campiñas" (f. 43r-v). De los que en la región de Arequipa se criaban observó Pereira que "son bastante útiles para conducir las harinas hasta Arica" (f. 14v), y de la dedicación de sus gentes, no solo de los camanejos, a la arriería, después de elogiar la calidad de sus caballos, dirá:

Las mulas no son menos apreciables. Con ellas se hace todo el tráfico del comercio de vinos y aguardientes de los valles a la ciudad, y particularmente a la Sierra. Todos los caudales que en barras pasan desde estas Reales Caxas a Lima para la fundición de moneda van en

10 Únicamente señalará Cevallos como ejemplo de tan "vicioso" hablar gallego que "los gallegos y asturianos puntúan la $v$ por la $u$ y así en lugar de Domingo dicen Dumengo, Turibio", y con semejante alarde lingüístico el académico, para quien "la maior diferencia está entre andaluces y castellanos en pronunciar más o menos fuerte la $h$ ", concluye: "Pero estos son vicios del vulgo incurables porque están apoyados de su misma ignorancia, y para curar estos males no escrive la Academia su Arte" (ibíd.).

11 Ciertamente no debe de ser casual que precisamente en América haya hormigas llamadas arrieras y un pájaro arriero, este descrito por Pichardo como cantarín y solitario (1862: 185). Varias menciones de la hormiga arriera se hallan en fuentes ecuatorianas, así esta de una relación de Chirinos del año 1808: "En orden a hormigas, las que llaman arrieras persiguen las mieses, las aucas y llunchie (o llinchis) y molestan con sus fuertes picaduras" (Ponce Leiva 1992: II, 766). 
estas vestias, y lo mismo sucede con los géneros que de aquella capital trahen a esta los comerciantes (f. 14).

El vocabulario soez y desgarrado ha sido corriente en boca de arrieros, tratantes de ganado mayor y trajinantes, jurar como un carretero es expresión referida al blasfemo impenitente, habiendo estado con frecuencia los miembros de estos gremios sujetos a la sospecha social y de la autoridad. El prototipo del individuo curtido en mil trabajos por los interminables caminos americanos podría ser aquel denunciado al Santo Oficio de México el año 1796 a causa de la canción El viaje del arriero, con letra de "proposiciones impuras, escandalosas y, lo que es más, sospechozas de heregía", donde un arriero dice que la mula cargada de bulas "se las fue comiendo, con lo que fue cagando por el camino las indulgencias", y el otro "que, llendo a tal lugar, hallaría una gran posada para sí y para sus bestias, pues hallaría una paja como unas ostias y un pesebre como un altar"12.

El léxico de la Proclama es de gentes acostumbradas al trato con animales de carga y de montura, "somos tan diestros en el manejo del cabrestrillo", alcabagar, aparejo, empacar, hociquera, lomillos, etc.; y, efectivamente se presenta a los camanejos como arrieros: "que aun los mismos animales de nuestras recuas, con ser más fuertes que todos nosotros juntos, nos han temido". Recurre el autor al insulto a la honra de los progenitores de Napoleón, "la cara de Dios no verá el hijo de p.", "se acordará muy bien de la mala p. que lo parió y del genísaro cabrón que lo engendró", así como a la puntada escatológica: "ellos le harán ver su gran cagada". Sin embargo, evidente es que esta pieza chusca está lejos de lo que debía de ser el lenguaje de El viaje del arriero, pues en el texto arequipeño la expresión socialmente inconveniente se reduce al simple esbozo de la crudeza léxica arrieril.

El estilo literario, las metáforas, símiles y juegos de palabras de la Proclama son propios de un autor culto, criollo seguramente orgulloso de su color, pues parece emplear jenízaro con el sentido de 'mestizo' que ya tenía en el primer diccionario académico, desde luego en su cita del chileno Ovalle (Real Academia Española 1726-1739/1969: II, 43) ${ }^{13}$. Tenía, pues, quien escribió este texto el preciso conocimiento lexicográfico, y con mayor

12 La denuncia inquisitorial está transcrita en el corpus novohispano de Company Company (1994: 616-617).

13 Carrión Ordóñez (1983: 260) cree que "indudablemente se esconde bajo del insulto una alusión al origen ítalo-francés de los Bonaparte"; pero, conociera o no la genealogía de Napoleón el autor de la Proclama, el baldón es para su padre en particular, como a la madre la trata de mala $p[u t a]$. 
seguridad aún el redactor del catecismo político publicado en Buenos Aires el año 1814, probablemente altoperuano o muy relacionado culturalmente con Charcas, porque su explicación "cholo en América quiere decir lo mismo que jenizaro en Europa, por ser engendrado por dos personas de diversa nación" (Sagredo Baeza 2009: 48, 121), con sintagma que constaba en la definición del Autoridades ('el hijo de padres de diversa nación'), mantenida en las siguientes ediciones del diccionario académico y que Terreros y Pando trasladó al suyo (1786-1793/1987: II, 383) ${ }^{14}$.

Advierte Carrión Ordóñez que camanejo es "denominación habitual sin connotaciones despectivas", salvo que "en Arequipa, por rivalidad lugareña, ha tomado notas negativas" (1983: 209), de manera que la atribución de cualidades a los naturales de Camaná no pasa del puro tópico, basado solo en el resentimiento, con frecuencia gratuito, entre pueblos vecinos, seguramente sin más pie en este caso que la mayor importancia de Arequipa como centro regional de la administración civil y eclesiástica, de nuevo el manido contraste entre lo urbano y lo rural ${ }^{15}$. Pero a no ser que hubiese algún motivo de diversidad lingüística, algo que más adelante se discutirá, ninguna razón asistirá al autor de la Proclama para equiparar a camanejos y a gallegos si no era servirse de un lugar común de mayor difusión y de más recorrido histórico como refuerzo hilarante de su sátira.

\section{LA LENGUA DE LA PROCLAMA}

3.1. No hay muestras de vulgarismo vocálico o consonántico en este texto, y tanto apigualar como cabrestillo son casos de lexicalización de las correspondientes alteraciones fonéticas fijados antes de 1816 y mantenidos hasta hoy, aunque actualmente de difusión popular y rural; pero no es seguro que ambas voces fueran meros rusticismos a principios del siglo XIX. El seseo se manifiesta en el trueque de $s$ por $c$ y $z$ : despescuesarlos 'despescuezarlos', destrosos, genísaro, (h)osiquera, ladronaso, pobresitos,

14 No recoge en América esta acepción el diccionario de americanismos de la Asociación de Academias de la Lengua Española (2010), que curiosamente incluye dicha voz con variantes ortográficas en dos entradas (genizaro, jenízaro).

15 Los motivos de la acuñación de clichés despreciativos de comunidades regionales o locales son diversos, y en el caso del pastuso 'tonto, grosero', sin duda su acérrima fidelidad realista es lo que dio pie a tal apreciación en los demás neogranadinos. 
sencerrillos, surriaga, vasa 'baza' ("no pierden vasa en robar azeitunas"); y de $z$ por s: compaz, manzo, manza (manzos corderos, manza paloma, maza (“maza hecha con maíz y azúcar”).

Aunque Pereira copia con sumo cuidado la Proclama del arequipeño, no puede asegurarse que estas mismas cacografías figuraran en el original, aunque el detalle resulta lingüísticamente indiferente, pues el seseo del canario y el del peruano eran idénticos, semejantes las faltas ortográficas que esta pronunciación les hacía cometer, como igual era la indiferencia de un natural de Canarias y de un americano ante la comisión de tales faltas. De hecho el lapsus seseoso abunda en todos los escritos del clérigo tinerfeño, que no se preocupa por su enmienda salvo en algún caso excepcional, como es un Saragoza corregido Zaragoza en la leyenda del dibujo Verdadera ymagen del Pe. Alonso Mesía, de c. 1815 (González Yanes 2002: 213).

3.2. En el apartado gramatical se advierte el uso del artículo en femenino la ante sustantivo de este género con /a/ tónica inicial, la alma, combinación que ya condenaba Juan de Valdés frente a la variante eufónica con el, rasgo tradicional, pues, que si se registraba ocasionalmente, a comienzos del XIX aún no demostraba marcada vulgaridad. El aspecto tradicional de este giro se refuerza con la falta del artículo en sintagma prepositivo: "queriendo capujarle a señor Fernando, nuestro rey, el trono", "al buen alaja de tío Chepe" y "nuestra Madre y Señora de Mercedes"; pero "N. S. de los Dolores", etc. La doble determinación nominal, con demostrativo más posesivo antepuestos al sustantivo, se da en la cita "con esa su maldita media luna", construcción del estilo formal que ha mantenido mayor vitalidad en América; y ya resultaba arcaizante la enclisis pronominal al participio del tiempo compuesto, con elisión del auxiliar, del segundo verbo de una coordinación, "después de haberlos sacado con engañifas de Madrid, y sacádolos a su inicua Francia", tendencia morfosintáctica de la que quedan huellas marginales y en declive en el español americano actual.

El conjunto de rasgos gramaticales hasta aquí señalados da un aire de arcaísmo al texto por referencia a lo que era el español peninsular de la época en el nivel culto, aspecto tradicional que en apreciable medida caracteriza diacrónica y sincrónicamente al español americano. En esta línea se sitúa el reiterado empleo de verbos en - $r a$ con valor modal intermedio entre el etimológico y el moderno imperfecto de subjuntivo equivalente a la forma en -se, del estadio evolutivo aún corriente en el siglo XVI; "si este vil traídos 
cayera a nuestras manos, no se viera de polvo ni se riera; tuviera, sí, bastante sarna que rascar y se acordara muy bien de la mala p. que lo parió" ${ }^{16}$.

La Proclama comienza con leísmo de persona, en toda ella no hay pasajes con lo o le complemento directo de cosa, tanto singular como plural, casi sistemático en los folios 57-57v; alabarles, le vencerán, le pondrán, le pescáramos, alcabagarle, le ayudaríamos, con las excepciones de lo auxiliaremos y desollarlo; pero a partir de ahí todo es distinción etimológica: lo parió, lo engendró, atollarlo, haberlos sacado, llevádolos, los apigualó, catatarlos, despescuesarlos, atolondrémoslo. Es muy llamativa esta particularidad textual, tal vez explicable, pero esto es una mera suposición, porque Pereira se decidiera a copiar con rigor también gramatical, el original arequipeño, con su probable distinción lo/le, pues en su parte personal de la Noticia como complemento de cosa tanto en singular como en plural generalmente usa lo, con algún ejemplo raro de leísmo, v. gr. "su estampa, diversidad de pasos, fogosidad y mansedumbre (de los caballos de Chile y de Lima) les hace recomendables" (f. 14), mientras que para persona distinción y confusión pronominal alternan corrientemente en singular, $\mathrm{p}$. ej.: lo (al caminante) despide (f. 11), acompañarlo (al intendente) (f. 20), le (al orador) acompaña (f. 20v), con predominio del uso etimológico, sobre todo en plural ${ }^{17}$.

La lengua de la Proclama desde el punto de vista gramatical es la general, con ciertos usos arraigados en la tradición, algunos declaradamente arcaizante, como de tal nota diacrónica ya era la ausencia del artículo en sintagmas preposicionales (tipo a señor Fernando) y otros hasta hoy caracterizadores del español americano, cual es el juego y distribución entre amara y amase, y sobre todo la continuidad del estadio semánticamente evolutivo que siguió al valor de las antiguas formas etimológicas en - $r a$, vigente en el XVI, siglo fundacional de la variedad de nuestra lengua en

16 Salvo en el primer caso (cayera), en los demás es claro el sentido hipotético, que los hace intercambiables con formas verbales en -ría. De nuevo hay -ra en "ojalá N. S. de los Dolores... nos hiciera el flaco servicio...", y -se en "después de haberlos sacado con engañifas de Madrid y llevádolos a su inicua Francia para que se divirtiesen y paseasen a pierna suelta"; alternan en "ojalá le pescáramos..., que a más de ponerle una buena osiquera... le claváramos dos tercios famosos de camotes..., y aunque con el peso se empacase, lo auxiliaremos y le ayudaríamos también con una buena suriaga". Podrían intercambiarse -ra y -se en pescáramos y empacase, pero no con claváramos; y en cuanto al futuro auxiliaremos, su é está acentuada en el manuscrito, tal vez suponga un descuido por auxiliáramos.

17 Con todo, debe advertirse que en la lengua escrita, tanto de España como de América, el leísmo de influencia literaria se dio con diversa profusión incluso en autores de dominios distinguidores. También que el leísmo modernamente ha conocido un notable desarrollo en Canarias, territorio antaño fundamentalmente distinguidor. 
América, y expresamente reconocido por Valdés. Todo ello conformaba la identidad de la variación transatlántica, lo mismo que el registro de bien para la formación del superlativo, "bien mancarrones somos", por entonces mucho más frecuente en América que en España, el del refuerzo de la inmediatez de lueguito, con atención a su característico diminutivo, que supone la locución "lueguito en el momento los apigualó", y el de demasiado con el sentido de "mucho': "el guarapo que demasiado nos alegra"18.

3.3. Donde más palmariamente destaca la peculiaridad dialectal, o la diferenciación diatópica de la Proclama, es en el léxico, pero no porque intencionadamente la considere el autor a fin de marcar la idiosincrasia dialectal del camanejo, los casos de posible rusticismo serían apigualó, cabrestillo y capujar, al que pretende estilísticamente referir la serie de términos familiares que en su composición acumula: al(h)aja, cascar, compa, desponchar, etc. Simplemente es el vocabulario propio de un criollo peruano, ocasionalmente recargado de coloquialismo con fines literarios, en el que hay americanismos generales, regionalismos de ámbito andino y quizá algún peruanismo, por exclusividad o de grado, $\mathrm{y}$ hasta posiblemente uno que otro localismo de la zona de Arequipa ${ }^{19}$. La diversidad diatópica precisamente la establece el copista, Pereira, en sus anotaciones explicativas del texto para su comprensión por el usuario del español europeo.

\section{CRUCES NORMATIVOS Y VARIACIÓN DIALECTAL}

4.1. La Proclama "que un chusco de Arequipa dio a luz en boca de los camanejos" (el subrayado es mío) es el intento fallido de ofrecer al público la figura del individuo inculto y rural de torpe expresión, un episodio ficticio más de los muchos que las letras hispánicas, con participación o

18 En un autor culto, como sin duda fue el de la Proclama, quizá más que una concesión a lo popular sea muestra de conservadurismo idiomático la reiteración en el uso durante siglos canónico de alquilémosnos y remontémosnos.

19 La concreción de la dimensión diatópica del léxico americano de la Proclama se concretará, en lo que posible sea, por la consulta de diccionarios especializados, pero no pocos datos de interés sobre el particular ofrece en su Vocabulario etimológico de la Noticia de Arequipa Carrión Ordóñez (1983: 185-350). 
aceptación popular, produjeron desde los albores del humanismo renacentista a partir de la contraposición entre el hablante cortesano y el labriego o pastor, entre la ciudad y la aldea. Aquí únicamente el eco del viejo tópico acuñado por la creación literaria se oye, marcado en la explicación titular y en la representación del "gracioso", con medios que, sin embargo, no son los propios del rústico hablante ni del ingenio primario, sino fruto de la elaboración intelectual del culto. Pero, por más que el de Arequipa no descienda a lo que podría ser el lenguaje rural o popular identificado en un camanejo, aunque pudiera ser de forma arbitraria o con los asendereados rasgos fonéticos que configuraron el estereotipo del hablante vulgar, es lo cierto que en el mismo argumento de su Proclama subyace la visión dicotómica que solía tenerse del español americano en el aspecto sociocultural.

Es, pues, la norma culta americana la que este texto descubre, con alguna particularidad regional; pero seguramente no la de la elite más cultivada, en cuyos escritos no he hallado un arcaísmo gramatical para la época tan marcado como era la ausencia del artículo en ciertos complementos preposicionales. Su comparación lingüística podría hacerse en referencia al español peninsular, y con mayor razón respecto de la modalidad canaria de Pereira, asimismo caracterizada por un marcado componente tradicional. De hecho en la Noticia el tinerfeño varias veces se muestra familiar con esta construcción, p. ej.: "el día de Purificación" (f. 21v), "el día de Concepción" (f. 25), "para la función de Corpus" (ilustración 42): ¿coincidencia normativa o, en este caso, desvío del original por el hábito dialectal del copista?

4.2. La coincidencia en el seseo entre el peruano y el canario no requiere de mayor comentario; en cuanto al problema del yeísmo, la Proclama no tiene indicio alguno del fenómeno, y, sin embargo, en los Nombres provinciales de la ciudad de Arequipa, cuyo autor es Pereira, parece haber una prueba de su existencia en dicha ciudad, aunque no podría decir con qué implantación social, pues pone sapayo como término local sinónimo de calabaza (f. 48a): cabría preguntarse, pues, si el yeísmo sería exclusivo de Arica y otros pueblos de la costa, como el canario afirma (cfr. 4.3.), y si no se había extendido ya hasta las estribaciones andinas. Tenerife por entonces era distinguidor, Alvar todavía registró una alta pervivencia de la palatal lateral en la isla (1959: 40-42), de manera que el isleño debió de aprender el vocablo de oído y no en la escritura. En manuscrito de Trujillo de finales del XVIII se encuentran ejemplos yeístas, también en cartas de Cóndor y del Cuzco de 1689, 1696 y 1722 (Frago 2010: 169, 171-172). 
Del antihiatismo, rasgo vocálico de tanta incidencia en el español americano, no hay rastro en la Proclama, sin duda contenido por el cultismo del autor. Ahora bien, Pereira lo manifiesta en voces por él nunca antes oídas, codeador, cospear (Carrión Ordóñez 1983: 215, 217), cuando a pedigüeño y tirar coces respectivamente señala los localismos codiador y cospiar (fs. 48d,f), y respeta el del Cielito de Potosí "Mi madre, por pasiadora" (f. 55), por fidelidad a la letra y porque la adecuación de la diptongación al metro, a pesar de que este tipo de antihiato, aun existiendo también en su tierra natal, no era de su preferencia.

4.3. A Pereira le interesó la diversidad dialectal del español, sin duda. Lo demuestra al recordar en carta a un amigo el habla rural canaria en la forma uyido puesta en boca del campesino, oído con alteración de la vocal inicial átona del participio y epéntesis consonántica antihiática: "semejante cosa no he uyido" (González Yanes 2002: 95), y argumentos de mayor peso para afirmarlo proporciona su confección del vocabulario arequipeño. En la Noticia afirma el andalucismo del español del Perú costeño, con noticia digna de tenerse en cuenta para la historia del yeísmo en este territorio:

Tanto aquí (Arica), como en los demás pueblos de esta costa, sus habitantes cortan el castellano como los andaluces, dándole a la $y$ el valor de $l l$, y por la inversa; solo si no hacen tanto uso de la $z$, con lo que suavizan más la expresión (f. 46v).

Así dará su opinión sobre el habla de la ciudad en la que ejerció el ministerio eclesiástico, certera en la consideración genérica sobre el léxico y en lo referente al uso exclusivo del castellano en tal centro urbano, y un tanto tópica en lo demás: "En Arequipa solo se habla la lengua castellana, pero con tanta finura, suavidad y propiedad como pudiera en las ciudades más cultas de España. Hay, sí, sus nombres provinciales, como sucede en todas partes" (f. 6).

En la Noticia se comprueba igualmente la capacidad de adaptación de Pereira al medio de su destino peruano, pues con pocos años de residencia su obra muestra indicios de criollización lingüística, en el léxico por la asimilación de americanismos como, por ejemplo, ocurre con molestoso, "por lo molestoso que les es el sol" (f. 42v) y vereda 'acera' en la descripción de Arequipa: "las calles están tiradas a cordel, de bastante anchura, y empedradas y enlosadas por sus veredas casi todas" (f. 3). Aunque no deja de revelar preferencias dialectales cuando en la Proclama a camote, de uso peruano, lo anota batata, también registrado en el cuerpo de la Noticia (f. 
12), denominación taína de un tubérculo que ya se consumía en Canarias a mediados del siglo XVI, y que en el vocabulario arequipeño pone como forma canónica frente al que considera provincialismo, camote. Y su canariedad asimismo aparece cuando da la preferencia a paila, en las Islas 'caldera o vasija para la cochura del guarapo', sobre perol. En lo gramatical está su familiar empleo del americano recién: "de cuyos estragos hay hasta el día vestigios, y otros que recién se están reparando" (f. 2v); la construcción en la mañana: "luego que con algún corto trabajo en la mañana ganan para comer..." (f. 34v), y la tendencia a formar el superlativo con bien, así en "fundando con ellos cuatro o cinco pueblos bien numerosos" (f. 1v).

4.4. El estudio del manuscrito de Pereira anuncia, en la parte correspondiente a la Proclama chusca, la identificación de un lenguaje rústico que, más allá de la intención literaria, no llega a cuajar en el texto, hablar de cuya vigencia sincrónica por muchas otras fuentes tenemos constancia, matizado de variantes diatópicas en el mapa americano. La diferenciación entre el uso vulgar o popular y el culto se encara sin distorsiones tópicas en el vocabulario arequipeño reunido por el clérigo canario, quien pretende ilustrar con sus datos una microgeografía lingüística limitada a Arequipa, tal vez también al entorno de esta ciudad, aunque de ellos se extraen referencias a un dominio regional más amplio, pero también al español general de América y al de Europa, en especial al de Canarias. Se comprueba, así, una vez más que difícilmente se puede pensar en el uso lingüístico sin tener en cuenta los cruces normativos y la variedad dialectal del español, y que entre la cúspide y la base de la pirámide sociolingüística, la parte culturalmente alta asimismo con su diversidad, median otros niveles en los que se identifican diferentes comunidades de hablantes.

\section{REFERENCIAS BIBLIOGRÁFICAS}

Alvar, Manuel. 1959. El español hablado en Tenerife. Madrid: Consejo Superior de Investigaciones Científicas.

Alvar Ezquerra, Manuel. 2000. Tesoro lexicográfico de las hablas andaluzas. Madrid: Arco Libros.

Anglés y Gortari, Matías. 1769/2007. Copia del informe que hizo el general D. Mathías de Anglés y Gortari, corregidor del Potosí, sobre los puntos que han sido causa de las discordias sucedidas en la ciudad de la Asunción de la provincia del Paraguay, y motivaron la persecución de D. Josef de Antequera por parte de los regulares de la Compañia. Madrid: Facsímiles Extramuros. 
Asociación de Academias de la Lengua Española. 2010. Diccionario de americanismos. Lima: Santillana Ediciones Generales.

Carrión OrdóÑez, Enrique. 1983. La lengua en un texto de la Ilustración. Lima: Pontificia Universidad Católica del Perú.

Castro y Rosal, Adolfo de. 1857. Nombres antiguos de las calles y plazas de Cádiz. Cádiz: Imprenta de la Revista Médica.

Company Company, Concepción. 1994. Documentos lingüisticos de la Nueva España. Altiplano Central. México: Universidad Nacional Autónoma.

De Cristóforis, Nadia. 2010. Bajo la Cruz del Sur: gallegos y asturianos en Buenos Aires (1820-1870). Santiago de Compostela: Consello da Cultura Galega - Fundación Pedro Barrié de la Maza.

Frago, Juan Antonio. 1986. "Tópicos lingüísticos y tipos cómicos en el teatro y en la lírica de los siglos XVI-XVIII”. Philologia Hispalensis 1, 85-116.

2010. El español de América en la Independencia. Santiago de Chile: Taurus.

González Yanes, Emma. 2002. El prebendado don Antonio Pereira Pacheco. La Laguna: Instituto de Estudios Canarios.

Hernández González, Manuel (ed.). 2009. Antonio Pereira Pacheco. "Noticia histórica de Arequipa". Santa Cruz de Tenerife: Ediciones Idea.

Pichardo, Esteban. 1862. Diccionario provincial casi razonado de vozes cubanas. La Habana: Imprenta la Antilla.

Ponce Leiva, Pilar (ed.). 1992. Relaciones histórico-geográficas de la Audiencia de Quito (siglo XVI-XIX). Madrid: Consejo Superior de Investigaciones Científicas.

Real Academia Española. 1726-1739/1969. Diccionario de Autoridades. Madrid: Editorial Gredos.

1771/1984. Gramática de la lengua castellana. Madrid: Editora Nacional.

Sagredo Baeza, Rafael. 2009. De la Colonia a la República. Los catecismos políticos americanos, 1811-1827. Madrid: Fundación Mapfre y Ediciones Doce Calles.

Terreros y PANDo, EsteBAn. 1786-1793/1987. Diccionario castellano con las voces de ciencias $y$ artes. Madrid: Arco Libros. 